\title{
Screening and characterization of ternary oxides for high temperature carbon capture
}

Michael W. Gaultois, ${ }^{1, \text { a) }}$ Matthew T. Dunstan, ${ }^{1}$, 国) Adam W. Bateson, ${ }^{1}$ Martin S. C. Chan, ${ }^{2}$ and Clare P. Grey, (b)

${ }^{1)}$ Department of Chemistry, University of Cambridge, Cambridge, CB2 1EW, United Kingdom

${ }^{2)}$ Department of Chemical Engineering and Biotechnology, University of Cambridge, Cambridge, CB2 3RA, United Kingdom

Carbon capture and storage (CCS) is increasingly being accepted as a necessary component of any effort to mitigate the impact of anthropogenic climate change, as it is both a relatively mature and easily implemented technology. High-temperature $\mathrm{CO}_{2}$ absorption looping is a promising process that offers a much lower energy penalty than the current state of the art amine scrubbing techniques, but more effective materials are required for widespread implementation. This work describes the experimental characterisation and $\mathrm{CO}_{2}$ absorption properties of several new ternary transition metal oxides predicted by high-throughput DFT screening. One material reported here, $\mathrm{Li}_{5} \mathrm{SbO}_{5}$, displays reversible $\mathrm{CO}_{2}$ sorption, and maintains $\sim 72 \%$ of its theoretical capacity out to 25 cycles. The results in this work are used to discuss major influences on $\mathrm{CO}_{2}$ absorption capacity and rate, including the role of the crystal structure, the transition metal, the alkali or alkaline earth metal, and the competing roles of thermodynamics and kinetics. Notably, this work shows the extent and rate to which ternary metal oxides carbonate is driven primarily by the identity of the alkali or alkaline earth ion and the nature of the crystal structure, whereas the identity of the e transition ion carries little influence in the systems studied here.

\section{INTRODUCTION}

The most expensive process in all carbon capture and sequestration strategies is the separation of $\mathrm{CO}_{2}$ from waste streams, making the discovery of suitable materials for separation processes a critical step to achieving a neutral carbon footprint. 1 . One technology that has shown recent promise is high-temperature $\mathrm{CO}_{2} \mathrm{ab}$ sorption looping, where a material first chemically reacts with $\mathrm{CO}_{2}$ to form a solid carbonate phase which is then heated in a second reactor to decompose and release pure $\mathrm{CO}_{2}$ and regenerate the starting material. Cabased sorbents, such as limestone, are the most widely tested and used materials for this purpose, ${ }^{2[3}$ and while being abundant and cheap, their $\mathrm{CO}_{2}$ absorption capacity rapidly decays with use because of undesirable changes to the microstructure of the cycled $\mathrm{CaCO}_{3}$ particles. 4

The deficiencies in the $\mathrm{CaO}-\mathrm{CaCO}_{3}$ system have motivated the exploration of various alternative ternary metal oxide phases, including $\mathrm{Li}_{2} \mathrm{ZrO}_{3},{ }^{5 / 6]} \mathrm{Na}_{2} \mathrm{ZrO}_{3}$, 78 $\mathrm{Li}_{4} \mathrm{SiO}_{4},{ }^{9,10} \mathrm{Li}_{5} \mathrm{AlO}_{4}{ }^{11112}$ and $\mathrm{Li}_{5} \mathrm{FeO}_{4}{ }^{13}$ In particular, the perovskite material $\mathrm{Ba}_{4} \mathrm{Sb}_{2} \mathrm{O}_{9}$ was found to be able to carbonate reversibly with negligible capacity loss even after 100 cycles, $\frac{14}{14}$ underlining the importance of searching for new materials with optimal $\mathrm{CO}_{2}$ absorption properties.

Towards this goal, a previous study performed a large scale screening of the Materials Project database (www.materialsproject.org), ${ }^{[15}$ which contains the structural and theoretical ground state energies of over 67000 solid state materials. After calculating the carbonation enthalpies of over 432 ternary oxide phases, a number of candidates with desirable predicted properties were synthesised and characterised to validate the

\footnotetext{
a) these authors contributed equally

${ }^{b)}$ Electronic mail: cpg27@cam.ac.uk
}

screening method. While these experiments confirmed the relative accuracy of the screening methodology in predicting the reaction thermodynamics of the studied materials, they did not account for variations in kinetics or cycle stability, with many promising candidates such as $\mathrm{Mg}_{6} \mathrm{MnO}_{8}, \mathrm{Ca}_{4} \mathrm{Nb}_{2} \mathrm{O}_{9}$ and $\mathrm{Na}_{3} \mathrm{SbO}_{4}$ failing on one or both of these requirements. Furthermore, while many promising candidates were obtained from the screening, most were not tested in this initial wave of experimental exploration and validation.

In this work, we used the results of the highthroughput DFT screening as the starting point for a more extensive experimental screening. 9 ternary metal oxide materials were prepared to investigate the role of crystal structure and chemical composition on the rate and reversibility of $\mathrm{CO}_{2}$ absorption reactions. The predicted carbonation behaviour, $\mathrm{CO}_{2}$ capacity and reaction are summarised in Table I. The entry for $\mathrm{Li}_{6} \mathrm{WO}_{6}$ was calculated directly from the Materials Project, as the initial screening omitted it due to the phase being unstable with respect to other phases in the phase diagram. The entry for $\mathrm{Ca}_{3} \mathrm{WO}_{6}$ was directly calculated in a similar fashion due to it being added to the database after the original screening.

The materials chosen here were selected for several reasons. $\mathrm{Li}_{6} \mathrm{MnO}_{4}$ and $\mathrm{Li}_{6} \mathrm{ZnO}_{4}$ have similarly high theoretical gravimetric $\mathrm{CO}_{2}$ absorption capacities as $\mathrm{Li}_{5} \mathrm{AlO}_{4}$ and $\mathrm{Li}_{5} \mathrm{FeO}_{4}$ and can be regenerated at lower temperatures than the formerly studied materials, possibly allowing more efficient cycling. $\mathrm{Li}_{2} \mathrm{WO}_{4}, \mathrm{Li}_{4} \mathrm{WO}_{5}$, and $\mathrm{Li}_{6} \mathrm{WO}_{6}$ all lie in the complex Li-W-O phase diagram, where the existence of small energy differences between multiple stable phases may allow rapid and stable cycling between different phases during carbonation, much like the $\mathrm{Li}-\mathrm{Si}-\mathrm{O}$ system. ${ }^{16}$ The materials from the $\mathrm{Ca}-\mathrm{W}-$ $\mathrm{O}$ phase diagram, $\mathrm{CaWO}_{4}$ and $\mathrm{Ca}_{3} \mathrm{WO}_{6}$, were chosen to determine the effect of changing the alkali element and how $\mathrm{W}$ substitution influences the $\mathrm{CaO}-\mathrm{CaCO}_{3}$ carbona- 
TABLE I. Carbonation reactions and carbonation temperatures under $p_{\mathrm{CO}_{2}}=1 \times 10^{4} \mathrm{~Pa}$ of materials studied in this work, compared to the prototypical $\mathrm{CaO}$ sorbent. Carbonation temperatures were derived from $\Delta H$ and $\Delta S$ values largely determined by DFT calculations performed in a previous large scale screening of the Materials Project database ${ }^{15}$ (values for $\mathrm{Li}_{6} \mathrm{WO}_{6}$ and $\mathrm{Ca}_{3} \mathrm{WO}_{6}$ were calculated as part of this study).

\begin{tabular}{|c|c|c|c|}
\hline Compound & $\begin{array}{l}T_{\text {carbonation }} \\
\quad(\mathrm{K})\end{array}$ & $\begin{array}{c}\mathrm{CO}_{2} \text { capacity } \\
\left(\mathrm{g}_{\mathrm{CO}_{2}} / \mathrm{g}_{\text {sorbent }}\right)\end{array}$ & Reaction \\
\hline $\mathrm{CaO}$ & 704 & 0.785 & $\mathrm{CaO}+\mathrm{CO}_{2} \longrightarrow \mathrm{CaCO}_{3}$ \\
\hline $\mathrm{Li}_{3} \mathrm{SbO}_{4}$ & 532 & 0.213 & $\mathrm{Li}_{3} \mathrm{SbO}_{4}+\mathrm{CO}_{2} \longrightarrow \mathrm{LiSbO}_{3}+\mathrm{Li}_{2} \mathrm{CO}_{3}$ \\
\hline $\mathrm{Li}_{5} \mathrm{SbO}_{5}$ & 781 & 0.186 & $\mathrm{Li}_{5} \mathrm{SbO}_{5}+\mathrm{CO}_{2} \longrightarrow \mathrm{Li}_{3} \mathrm{SbO}_{4}+\mathrm{Li}_{2} \mathrm{CO}_{3}$ \\
\hline $\mathrm{Li}_{7} \mathrm{SbO}_{6}$ & 903 & 0.165 & $\mathrm{Li}_{7} \mathrm{SbO}_{6}+\mathrm{CO}_{2} \longrightarrow \mathrm{Li}_{5} \mathrm{SbO}_{5}+\mathrm{Li}_{2} \mathrm{CO}_{3}$ \\
\hline $\mathrm{Li}_{6} \mathrm{MnO}_{4}$ & 846 & 0.822 & $\frac{1}{3} \mathrm{Li}_{6} \mathrm{MnO}_{4}+\mathrm{CO}_{2} \longrightarrow \frac{1}{3} \mathrm{MnO}+\mathrm{Li}_{2} \mathrm{CO}_{3}$ \\
\hline $\mathrm{Li}_{6} \mathrm{ZnO}_{4}$ & 821 & 0.450 & $\frac{4}{7} \mathrm{Li}_{6} \mathrm{ZnO}_{4}+\mathrm{CO}_{2} \longrightarrow \frac{1}{7} \mathrm{Li}_{10} \mathrm{Zn}_{4} \mathrm{O}_{9}+\mathrm{Li}_{2} \mathrm{CO}_{3}$ \\
\hline $\mathrm{Li}_{6} \mathrm{ZnO}_{4}$ & 817 & 0.772 & $\frac{1}{3} \mathrm{Li}_{6} \mathrm{ZnO}_{4}+\mathrm{CO}_{2} \longrightarrow \frac{1}{3} \mathrm{ZnO}+\mathrm{Li}_{2} \mathrm{CO}_{3}$ \\
\hline $\mathrm{Li}_{2} \mathrm{WO}_{4}$ & 305 & 0.168 & $\mathrm{Li}_{2} \mathrm{WO}_{4}+\mathrm{CO}_{2} \longrightarrow \mathrm{WO}_{3}+\mathrm{Li}_{2} \mathrm{CO}_{3}$ \\
\hline $\mathrm{Li}_{4} \mathrm{WO}_{5}$ & 503 & 0.151 & $\mathrm{Li}_{4} \mathrm{WO}_{5}+\mathrm{CO}_{2} \longrightarrow \mathrm{Li}_{2} \mathrm{WO}_{4}+\mathrm{Li}_{2} \mathrm{CO}_{3}$ \\
\hline $\mathrm{Li}_{6} \mathrm{WO}_{6}$ & 1005 & 0.137 & $\mathrm{Li}_{6} \mathrm{WO}_{6}+\mathrm{CO}_{2} \longrightarrow \mathrm{Li}_{4} \mathrm{WO}_{5}+\mathrm{Li}_{2} \mathrm{CO}_{3}$ \\
\hline $\mathrm{CaWO}_{4}$ & 323 & 0.153 & $\mathrm{CaWO}_{4}+\mathrm{CO}_{2} \longrightarrow \mathrm{WO}_{3}+\mathrm{CaCO}_{3}$ \\
\hline $\mathrm{Ca}_{3} \mathrm{WO}_{6}$ & 949 & 0.330 & $\frac{1}{3} \mathrm{Ca}_{3} \mathrm{WO}_{6}+\mathrm{CO}_{2} \longrightarrow \frac{1}{3} \mathrm{WO}_{3}+\mathrm{CaCO}_{3}$ \\
\hline
\end{tabular}

tion reaction. $\mathrm{Li}_{5} \mathrm{SbO}_{5}$ has a reasonable gravimetric capacity without requiring high temperatures for regeneration, and provides another point of reference for the role that $\mathrm{Sb}$ plays in CCS materials in light of previous work on Sb-containing ternary oxides, such as $\mathrm{Ba}_{4} \mathrm{Sb}_{2} \mathrm{O}_{9} \cdot 14$

Taken as a whole, the selection of materials studied here allows us to study the impact of chemical, structural and thermodynamic factors on CCS performance, working towards the twin goals of materials discovery and increased fundamental understanding of structural evolution during carbonation. It also allows further validation of the original screening methodology to improve future studies.

\section{METHODS}

Materials were prepared using ceramic methods; stoichiometric amounts of solid precursor powders were ground together in an agate mortar and pestle, then reacted at high temperatures under air or argon. Owing to the wide range of materials, the same processing conditions could not be used for every materials; the precursors for each material, along with the processing schedule and atmosphere, are summarised in Table II. The reactions involving $\mathrm{LiOH}$ were pretreated at $423 \mathrm{~K}$ for $1 \mathrm{~h}$ in air to remove volatile components. Most complications in preparation or carbonation arose from melting of samples.

To analyse structural changes upon carbonation, a portion of the prepared material was subsequently annealed under a flow of pure $\mathrm{CO}_{2}$ in a tube furnace at $973 \mathrm{~K}$ for $2 \mathrm{~h}\left(723 \mathrm{~K}\right.$ for $\left.\mathrm{Li}_{4} \mathrm{WO}_{5}\right)$. Both the as-prepared and carbonated samples were characterised using room temperature powder X-ray diffraction (XRD), performed on a
PanAlytical Empyrean diffractometer in Bragg-Brentano geometry using $\mathrm{Cu} \mathrm{K}_{\alpha}$ radiation. The instrument contributions to the peak shape were determined using a diffraction pattern of NIST SRM Si 640c collected in a separate measurement. Rietveld and Pawley refinement were performed using the Topas software package. ${ }^{17}$ In situ XRD measurements above room temperature were performed using an Anton-Paar XRK 900 furnace, with a total gas flow rate of $100 \mathrm{~mL} \mathrm{~min}^{-1}$.

The carbonation and regeneration reactions of the screened materials were investigated with thermogravimetric analysis (TGA) (TGA/DSC 1, Mettler Toledo) operating at atmospheric pressure. In each experiment, a sample of $\sim 20 \mathrm{mg}$ of powder was placed in a $70 \mu \mathrm{L}$ $\mathrm{Al}_{2} \mathrm{O}_{3}$ crucible, supported on a cantilever-type balance. The reaction chamber was heated by a tube furnace surrounding the balance. Both the protective gas and the purge gas were $\mathrm{N}_{2}$, and were fed to the TGA reaction chamber from a common source with a total flow rate of $100 \mathrm{~mL} \mathrm{~min}^{-1}$. The reactive gas was either $\mathrm{N}_{2}$ or $\mathrm{CO}_{2}$, fed by a capillary so that the gas could flow over the top of the crucible. The partial pressure of $\mathrm{CO}_{2}$ at the surface of the solid sample was adjusted by varying the mix of $\mathrm{N}_{2}$ and $\mathrm{CO}_{2}$ in the reactive gas, while keeping a constant overall flow rate of $100 \mathrm{~mL} \mathrm{~min}^{-1}$. The supply of reactive gas was controlled by solenoid valves, allowing automatic changing of reactive gas at different points within the TGA program. The actual $\mathrm{CO}_{2}$ concentration at the gas-solid interface was calibrated against the well-understood thermodynamic $\mathrm{CaO} / \mathrm{CaCO}_{3}$ carbonation equilibrium. Over a range of different $p_{\mathrm{CO}_{2}}$, the temperature of the onset of $\mathrm{CaCO}_{3}$ decomposition was recorded and the corresponding $\mathrm{CO}_{2}$ partial pressure in contact with the solid phase was determined from the phase diagram of the $\mathrm{CaO}-\mathrm{CaCO}_{3}-\mathrm{CO}_{2}$ system. 
TABLE II. List of precursor materials and processing schedules used during the solid-state preparation of the screened CCS materials.

\begin{tabular}{cccc}
\hline \hline CCS material Precursor materials & Reaction programme & Atmosphere \\
\hline $\mathrm{Li}_{5} \mathrm{SbO}_{5}$ & $\mathrm{LiOH}$ and $\mathrm{Sb}_{2} \mathrm{O}_{5}$ & $973 \mathrm{~K} \mathrm{for} 24 \mathrm{~h}, 1073 \mathrm{~K}$ for $12 \mathrm{~h}$ & argon \\
$\mathrm{Li}_{6} \mathrm{MnO}_{4}$ & $\mathrm{Li}_{2} \mathrm{O}$ and $\mathrm{MnO}$ & $1223 \mathrm{~K} \mathrm{for} 12 \mathrm{~h}$ & argon \\
$\mathrm{Li}_{6} \mathrm{ZnO}_{4}$ & $\mathrm{LiOH}$ and $\mathrm{ZnO}$ & $973 \mathrm{~K} \mathrm{for} 24 \mathrm{~h}, 1073 \mathrm{~K}$ for $12 \mathrm{~h}, 1173 \mathrm{~K}$ for $24 \mathrm{~h}$ & argon \\
$\mathrm{Li}_{2} \mathrm{WO}_{4}$ & $\mathrm{LiOH}$ and $\mathrm{WO}_{3}$ & $973 \mathrm{~K}$ for $12 \mathrm{~h}$ & argon \\
$\mathrm{Li}_{4} \mathrm{WO}_{5}$ & $\mathrm{Li}_{2} \mathrm{O}$ and $\mathrm{WO}_{3}$ & $973 \mathrm{~K} \mathrm{for} 12 \mathrm{~h}, 1073 \mathrm{~K}$ for $12 \mathrm{~h}$ & argon \\
$\mathrm{Li}_{6} \mathrm{WO}_{6}$ & $\mathrm{Li}_{2} \mathrm{O}$ and $\mathrm{WO}_{3}$ & $973 \mathrm{~K} \mathrm{for} 48 \mathrm{~h}$ & air \\
$\mathrm{CaWO}_{4}$ & $\mathrm{CaCO}_{3}$ and $\mathrm{WO}_{3}$ & $1273 \mathrm{~K}$ for $12 \mathrm{~h}$ & air \\
$\mathrm{Ca}_{3} \mathrm{WO}_{6}$ & $\mathrm{CaCO}_{3}$ and $\mathrm{WO}_{3}$ & $1273 \mathrm{~K}$ for $48 \mathrm{~h}$ & air \\
\hline
\end{tabular}

For single cycle carbonation and regeneration TGA experiments, the material was heated from $323 \mathrm{~K}$ to $973 \mathrm{~K}$ at a rate of $10 \mathrm{~K} \mathrm{~min}^{-1}$, and then held at $973 \mathrm{~K}$ for $120 \mathrm{~min}$. In the case of $\mathrm{Li}_{6} \mathrm{ZnO}_{4}$ this temperature was held for only $10 \mathrm{~min}$. In the case of $\mathrm{Li}_{4} \mathrm{WO}_{5}$, the maximum temperature used was $732 \mathrm{~K}$. In each case $\mathrm{CO}_{2}$ was supplied as the reactive gas for the duration of the experiment. For the multiple cycling experiments of $\mathrm{Li}_{5} \mathrm{SbO}_{5}, \mathrm{Li}_{6} \mathrm{WO}_{6}$ and $\mathrm{Li}_{4} \mathrm{WO}_{5}$, the material was heated isothermally at $973 \mathrm{~K}\left(723 \mathrm{~K}\right.$ for $\left.\mathrm{Li}_{4} \mathrm{WO}_{5}\right)$ for $60 \mathrm{~min}$ under $p_{\mathrm{CO}_{2}}=1.05 \pm 0.12 \times 10^{5} \mathrm{~Pa}$, then heated to $1223 \mathrm{~K}$ ( $823 \mathrm{~K}$ for $\mathrm{Li}_{4} \mathrm{WO}_{5}$ ) and held at that temperature for 40 min under pure $\mathrm{N}_{2}$, before being cooled to $973 \mathrm{~K}$ (723 K for $\mathrm{Li}_{4} \mathrm{WO}_{5}$ ) and held for 20 min under $\mathrm{N}_{2}$. This sequence was repeated for 25 cycles of carbonation and regeneration. The samples obtained at the end of these cycles were characterised using room-temperature XRD as described above, along with other samples cycled in a tube furnace for 3 cycles, with a program of carbonation at $973 \mathrm{~K}$ for $2 \mathrm{~h}$ under pure $\mathrm{CO}_{2}$ followed by regeneration at $1223 \mathrm{~K}$ for $2 \mathrm{~h}$ under pure $\mathrm{N}_{2}$ (temperatures of $723 \mathrm{~K}$ and $823 \mathrm{~K}$ were used for $\mathrm{Li}_{4} \mathrm{WO}_{5}$ ).

Backscattered electron micrographs were collected using a field emission gun scanning electron microscope (Camscan MX2600) operating at an accelerating voltage of $10 \mathrm{kV} .10 \mathrm{~nm}$ of Pd was sputter-deposited on specimens to minimize charging.

The porosity and specific surface area (SSA) of the candidate materials were determined using volumetric sorption measurements (TriStar3000 analyzer, Micromeritics) in $\mathrm{N}_{2}$ at $77 \mathrm{~K}$. The SSA was calculated using Brunauer-Emmett-Teller (BET) analysis using $\mathrm{N}_{2}$ adsorption! 18

\section{RESULTS AND DISCUSSION}

\section{A. Characterisation of screened materials}

XRD was used to characterise the identity and purity of all materials, which were single-phase after preparation with the exception of $\mathrm{Li}_{6} \mathrm{MnO}_{4}$. Despite multiple different synthetic approaches, $\mathrm{Li}_{6} \mathrm{MnO}_{4}$ could not be pro- duced without the persistence of significant amounts of $\mathrm{MnO}$ and $\mathrm{Li}_{2} \mathrm{CO}_{3}$ (see Supporting Information). The material was still included in the initial thermogravimetric experiments, as $\mathrm{Li}_{6} \mathrm{MnO}_{4}$ and the impurities are expected to participate in the carbonation reactions.

The powder patterns of all materials and mixtures were well-fit by the structural models, except $\mathrm{Li}_{6} \mathrm{WO}_{6}$. The average crystal structure of $\mathrm{Li}_{6} \mathrm{WO}_{6}(\mathrm{Immm})$ is described by half-filled edge-sharing $\mathrm{WO}_{6}$ octahedra extending along the $b$ direction, and corner-sharing along the $c$ direction (Figure 1). The measured diffraction pattern of $\mathrm{Li}_{6} \mathrm{WO}_{6}$ contains sharp reflections well-modelled by the $I m m m$ spacegroup, along with several additional broad reflections with Warren-type lineshapes, beyond the expected reflections (Figure 11). This is consistent with the original report by Hauck, where extra reflections were attributed to partial ordering of $\mathrm{W}^{6+}$ ions ${ }^{19}$ in the formally half-filled $2 a$ site. This is sensible in light of Pauling's rules, where structures will seek to maximize the distance between highly charged centres to minimize the Coulombic energy penalty. In this case, given the high charge-radius ratio of $\mathrm{W}^{6+}$, it is energeticallyunfavourable to form edge-sharing pairs of $\mathrm{WO}_{6}$ octahe$\mathrm{dra}$, and $\mathrm{W}^{6+}$ orders on the $2 a$ site (at least locally) to minimize the system energy.

The surface area of the candidate materials was characterised using BET (see Supporting Information); all materials exhibit low surface areas $\left(\sim 1 \mathrm{~m}^{2} \mathrm{~g}^{-1}\right)$, which is expected as the ceramic methods used in the material preparation involve annealing at high temperatures for long dwell times. Owing to the similar, low surface areas, we do not expect sample morphology or surface area to be a factor in the relative performance of the pristine materials studied here.

Analysis of the materials after carbonation using roomtemperature XRD confirm the following reactions take place (diffractograms shown in Supporting Information):

$$
\begin{aligned}
& \mathrm{Li}_{5} \mathrm{SbO}_{5}+\mathrm{CO}_{2} \longrightarrow \mathrm{Li}_{3} \mathrm{SbO}_{4}+\mathrm{Li}_{2} \mathrm{CO}_{3} \\
& \frac{1}{3} \mathrm{Li}_{6} \mathrm{MnO}_{4}+\mathrm{CO}_{2} \longrightarrow \frac{1}{3} \mathrm{MnO}+\mathrm{Li}_{2} \mathrm{CO}_{3}
\end{aligned}
$$


(a)

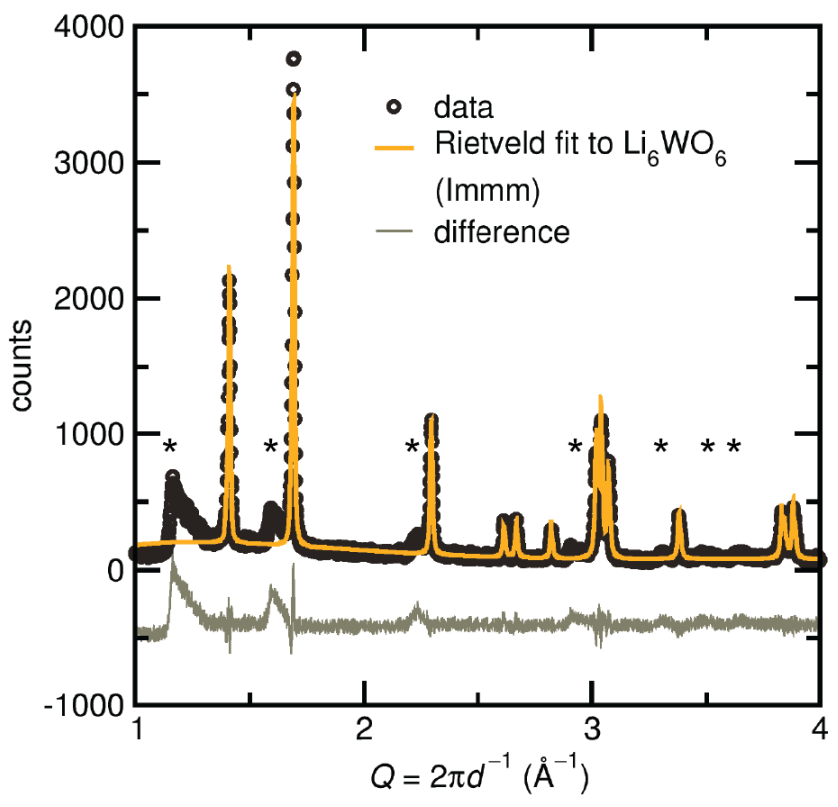

(b)

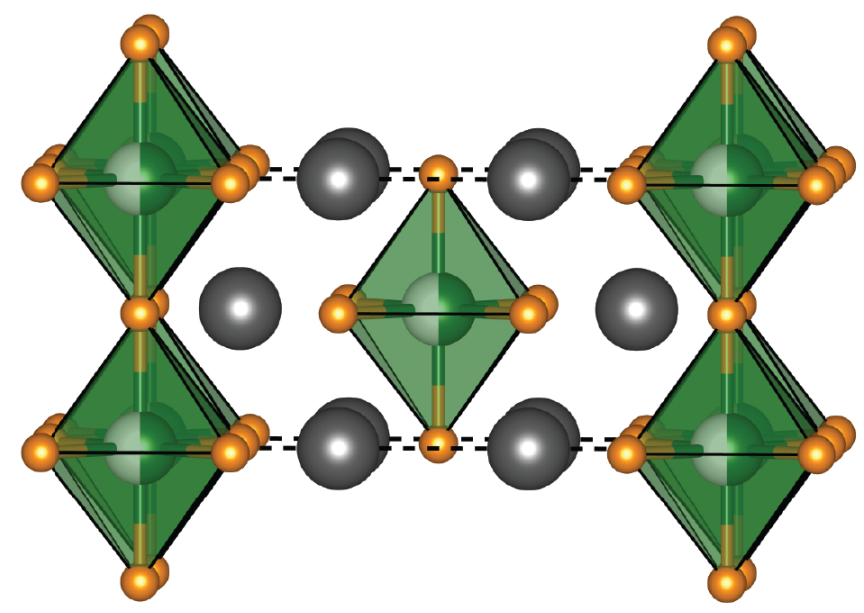

FIG. 1. (a) XRD pattern and Rietveld refinement of $\mathrm{Li}_{6} \mathrm{WO}_{6}$ in the $I m m m$ spacegroup $(\lambda=1.5405 \AA)$. Additional peaks with Warren-type broadening (*) are present due to ordering of $\mathrm{W}^{6+}$ ions in the half-filled $2 a$ site. It is energetically unfavourable to have edge-sharing octahedra, which would bring together highly-charged $\mathrm{W}^{6+}$ ions. Ordering of $\mathrm{W}$ to prevent edge-sharing $\mathrm{WO}_{6}$ pairs in the local structure lowers the system energy, and leads to the broadened extra reflections observed in the XRD pattern. (b) The average crystal structure of $\mathrm{Li}_{6} \mathrm{WO}_{6}$ $(\mathrm{Immm})$ is described by half-filled edge-sharing $\mathrm{WO}_{6}$ octahedra extending along the $b$ direction, and corner-sharing along the $c$ direction.

$$
\begin{aligned}
& \frac{1}{3} \mathrm{Li}_{6} \mathrm{ZnO}_{4}+\mathrm{CO}_{2} \longrightarrow \frac{1}{3} \mathrm{ZnO}+\mathrm{Li}_{2} \mathrm{CO}_{3} \\
& \mathrm{Li}_{4} \mathrm{WO}_{5}+\mathrm{CO}_{2} \longrightarrow \mathrm{Li}_{2} \mathrm{WO}_{4}+\mathrm{Li}_{2} \mathrm{CO}_{3} \\
& \mathrm{Li}_{6} \mathrm{WO}_{6}+\mathrm{CO}_{2} \longrightarrow \mathrm{Li}_{4} \mathrm{WO}_{5}+\mathrm{Li}_{2} \mathrm{CO}_{3}
\end{aligned}
$$

These results agree with the predicted carbonation reactions obtained from the Materials Project screening (Table II), with several exceptions. First, $\mathrm{CaWO}_{4}$, $\mathrm{Ca}_{3} \mathrm{WO}_{6}$ and $\mathrm{Li}_{2} \mathrm{WO}_{4}$ showed no evidence of carbonation in their diffractograms following exposure to flowing $\mathrm{CO}_{2}$ in a tube furnace, and were thus not subjected to any further experiments. Second, we observe that $\mathrm{Li}_{6} \mathrm{ZnO}_{4}$ carbonates to form $\mathrm{ZnO}$ and $\mathrm{Li}_{2} \mathrm{CO}_{3}$, rather than the products predicted by the screening $\left(\mathrm{Li}_{10} \mathrm{Zn}_{4} \mathrm{O}_{9}\right.$ and $\mathrm{Li}_{2} \mathrm{CO}_{3}$ ). This was more carefully confirmed by performing in situ XRD at 10 minute intervals during carbonation of $\mathrm{Li}_{6} \mathrm{ZnO}_{4}$ in atmospheres of $100 \% \mathrm{CO}_{2}$ and $50 \%$ $\mathrm{CO}_{2}\left(\mathrm{~N}_{2}\right)$, at $50 \mathrm{~K}$ intervals between $773 \mathrm{~K}$ and $973 \mathrm{~K}$; there was no evidence for the formation of $\mathrm{Li}_{10} \mathrm{Zn}_{4} \mathrm{O}_{9}$ nor other Zn species. Further, XRD measurements on $\mathrm{Li}_{6} \mathrm{ZnO}_{4}$ powder exposed to ambient lab atmosphere for prolonged periods revealed the presence of only $\mathrm{Li}_{6} \mathrm{ZnO}_{4}, \mathrm{ZnO}$, and $\mathrm{Li}_{2} \mathrm{CO}_{3}$.

For each material in the Materials Project, our screening metholodogy finds several different possible carbonation reactions, and ranks them based on the calculated carbonation enthalpy of each reaction. We select the reaction with the lowest (most negative) carbonation enthalpy and assume that it will be the only reaction that is activated.

Selecting the reaction with the lowest carbonation enthalpy works well when there is a reaction that is clearly more favourable than the other possibilities, but in this case the two reactions have extremely similar carbonation enthalpies, well within the errors of the underlying DFT metholodogy:

$$
\begin{array}{r}
\frac{1}{3} \mathrm{Li}_{6} \mathrm{ZnO}_{4}+\mathrm{CO}_{2} \longrightarrow \frac{1}{3} \mathrm{ZnO}+\mathrm{Li}_{2} \mathrm{CO}_{3} \\
\Delta H=-2.25 \mathrm{eV}\left(-217 \mathrm{~kJ} \mathrm{~mol}^{-1}\right) \\
\frac{4}{7} \mathrm{Li}_{6} \mathrm{ZnO}_{4}+\mathrm{CO}_{2} \longrightarrow \frac{1}{7} \mathrm{Li}_{10} \mathrm{Zn}_{4} \mathrm{O}_{9}+\mathrm{Li}_{2} \mathrm{CO}_{3} \\
\Delta H=-2.26 \mathrm{eV}\left(-217 \mathrm{~kJ} \mathrm{~mol}^{-1}\right)
\end{array}
$$

Selecting the reaction with the lowest carbonation enthalpy also neglects kinetic limitations, which are likely responsible for the inert behaviour of $\mathrm{CaWO}_{4}, \mathrm{Ca}_{3} \mathrm{WO}_{6}$ and $\mathrm{Li}_{2} \mathrm{WO}_{4}$ seen here. These kinetic considerations cannot be easily treated from thermodynamic quantities such as $\Delta H$ and $\Delta S$ calculated from the Materials Project. 


\section{B. Initial carbonation reaction thermogravimetry}

To investigate the initial carbonation capacity and kinetics of the candidate materials, ramp TGA experiments were carried out at a rate of $10 \mathrm{~K} \mathrm{~min}^{-1}$ (Figure 2). The experimental capacities and reaction temperatures for the initial carbonation step compared to the theoretical values from the Materials Project screening are summarised in Table III.

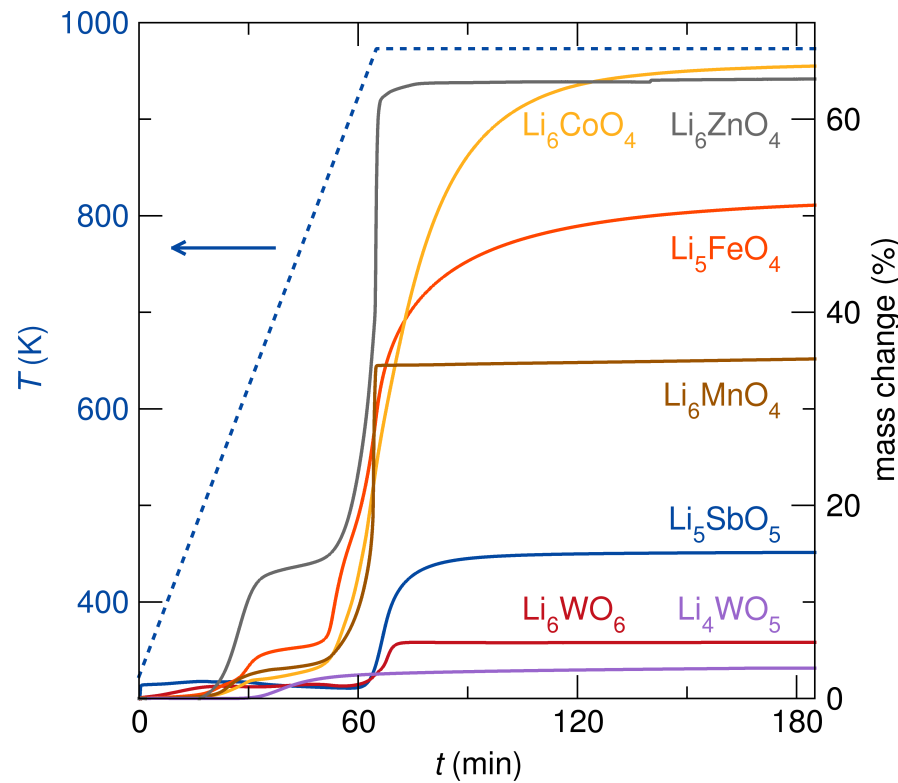

FIG. 2. TGA traces for selected candidate materials heated under $\mathrm{CO}_{2}\left(p_{\mathrm{CO}_{2}}=1 \times 10^{4} \mathrm{~Pa}\right)$. Most materials studied here exhibit similar carbonation profiles, with the onset of a small initial mass gain at low temperature around $\sim 600 \mathrm{~K}$ followed by a sharp onset and substantial mass gain initiated between $850 \mathrm{~K}$ and $900 \mathrm{~K}$. Traces from previous studies for $\mathrm{Li}_{5} \mathrm{FeO}_{4}$ and $\mathrm{Li}_{6} \mathrm{CoO}_{4}$ are added for comparisor $\frac{15}{15}$.

The initial TGA experiments are consistent with the $T_{\text {carbonation }}$ values obtained from the screening; the majority of materials lie within $\sim 100 \mathrm{~K}$ of their experimental values. This corresponds to an error of $\sim 10 \mathrm{meV}$, and is well within the limits of the DFT methodology. However, the experimental carbonation capacities are all lower than the corresponding theoretical limits, with some materials showing significant deviations (e.g. $\mathrm{Li}_{6} \mathrm{MnO}_{4}$, $\mathrm{Li}_{4} \mathrm{WO}_{5}$, and $\mathrm{Li}_{6} \mathrm{WO}_{6}$ ).

It is clear from the TGA ramp experiments that $\mathrm{Li}_{6} \mathrm{MnO}_{4}$ and $\mathrm{Li}_{6} \mathrm{ZnO}_{4}$ exhibit a two-stage carbonation behaviour, commonly observed in other materials with a similar chemical composition and structure such as $\mathrm{Li}_{5} \mathrm{AlO}_{4}, \mathrm{Li}_{5} \mathrm{FeO}_{4}$, and $\mathrm{Li}_{6} \mathrm{CoO}_{4}{ }^{[1] 13] 15}$ This two-stage carbonation features the onset of a small initial mass gain at low temperature around $\sim 600 \mathrm{~K}$ followed by a sharp onset and substantial mass gain initiated between $850 \mathrm{~K}$ and $900 \mathrm{~K}$. The low-temperature regime is ascribed to reactions near the surface, whereas the high sorption of
$\mathrm{CO}_{2}$ in the high-temperature regime is ascribed to bulk solid-state reaction, enabled by a sufficiently high rate of ionic transport activated at higher temperatures.

\section{Cycling experiments}

Of the materials that could initially carbonate, only $\mathrm{Li}_{5} \mathrm{SbO}_{5}, \mathrm{Li}_{4} \mathrm{WO}_{5}$ and $\mathrm{Li}_{6} \mathrm{WO}_{6}$ could be regenerated and cycled in the TGA. $\mathrm{Li}_{6} \mathrm{ZnO}_{4}$ and $\mathrm{Li}_{6} \mathrm{MnO}_{4}$ both show evidence of melting at the higher temperatures required for regeneration, most likely due to the formation of $\mathrm{Li}_{2} \mathrm{CO}_{3}$ (with a melting point of $996 \mathrm{~K}$ ), making them unsuitable for further use.

The materials that could be regenerated were cycled 25 times in the TGA; mass-time curves for the 1st, 2nd, 10th and 25th cycles are shown in Figure 3. The difference in mass after 60 minutes of exposure to $\mathrm{CO}_{2}$ at reaction temperature was used to determine the mass of $\mathrm{CO}_{2}$ absorbed, which was then used calculate the percentage of theoretical capacity according to the appropriate reaction stoichiometry shown earlier in Equations 1-5. The $\mathrm{CO}_{2}$ sorption capacity as a percentage of theoretical capacity for the material is plotted as a function of cycle number, along with the corresponding performance of $\mathrm{CaO}$ for comparison (Figure 4).

$\mathrm{Li}_{5} \mathrm{SbO}_{5}$ displays an initial carbonation capacity $>90 \%$ of the theoretical capacity, and while this quickly decreases to $\sim 75 \%$ by the 3 rd $\mathrm{CO}_{2}$ sorption/desorption cycle, $\mathrm{Li}_{5} \mathrm{SbO}_{5}$ displays excellent capacity retention for the duration of the cycling experiment (Figure 4), with $\sim 72 \%$ of the theoretical capacity after 25 cycles. Furthermore, in addition to the small decrease in capacity with cycling, the material shows much slower carbonation kinetics. In the first cycle, $\mathrm{Li}_{5} \mathrm{SbO}_{5}$ absorbs $70 \%$ of the theoretical capacity of $\mathrm{CO}_{2}$ within 5 minutes when exposed to $\mathrm{CO}_{2}$, whereas achieving the same sorption after 10 cycles takes 60 minutes (Figure 3).

$\mathrm{Li}_{6} \mathrm{WO}_{6}$ displays an initial carbonation capacity $\sim 70 \%$ of the theoretical capacity, and the sorption capacity decreases steadily as the material is cycled (Figure 4). By the 25th cycle, the $\mathrm{CO}_{2}$ sorption capacity is $\sim 35 \%$ of the theoretical capacity. The first cycle has an anomalous sorption capacity because some of the material was likely partially carbonated prior to the experiment, as $\mathrm{Li}_{6} \mathrm{WO}_{6}$ spontaneously carbonates in ambient conditions. Despite the steady degradation in sorption capacity as the material is cycled, $\mathrm{Li}_{6} \mathrm{WO}_{6}$ demonstrates impressive carbonation kinetics; the material reaches maximum capacity in less than 1 minute, with no change upon repeated cycling.

$\mathrm{Li}_{4} \mathrm{WO}_{5}$ displays poor $\mathrm{CO}_{2}$ sorption capacity compared to its theoretical capacity, but exhibits the most stable gravimetric capacity of all the materials studied here (Figure 4). $\mathrm{Li}_{4} \mathrm{WO}_{5}$ maintains a steady capacity of $\sim 20 \%$ out to 25 cycles studied here, and the carbonation kinetics improve as the material is cycled. Whereas in the first cycle after 5 minutes of exposure to $\mathrm{CO}_{2}$ only $\sim 6 \%$ of the 
TABLE III. Theoretically derived carbonation reaction parameters for the preliminary candidates selected for this study compared to the values obtained from TGA experiments under $p_{\mathrm{CO}_{2}}=1 \times 10^{4} \mathrm{~Pa}$.

\begin{tabular}{ccccc}
\hline \hline Compound & \multicolumn{2}{c}{$T_{\text {carbonation }}(\mathrm{K})$} & \multicolumn{2}{c}{$\mathrm{CO}_{2}$ capacity $\left(\mathrm{g}_{\mathrm{CO}_{2}} / \mathrm{g}_{\text {sorbent }}\right)$} \\
Expreening Experimental & Screening & Experimental \\
\hline $\mathrm{Li}_{5} \mathrm{SbO}_{5}$ & 781 & 890 & 0.186 & 0.151 \\
$\mathrm{Li}_{6} \mathrm{MnO}_{4}$ & 846 & 840 & 0.822 & 0.352 \\
$\mathrm{Li}_{6} \mathrm{ZnO}_{4}$ & 817 & 810 & 0.772 & 0.638 \\
$\mathrm{Li}_{4} \mathrm{WO}_{5}$ & 503 & 500 & 0.151 & 0.031 \\
$\mathrm{Li}_{6} \mathrm{WO}_{6}$ & 1005 & 880 & 0.137 & 0.058 \\
\hline
\end{tabular}
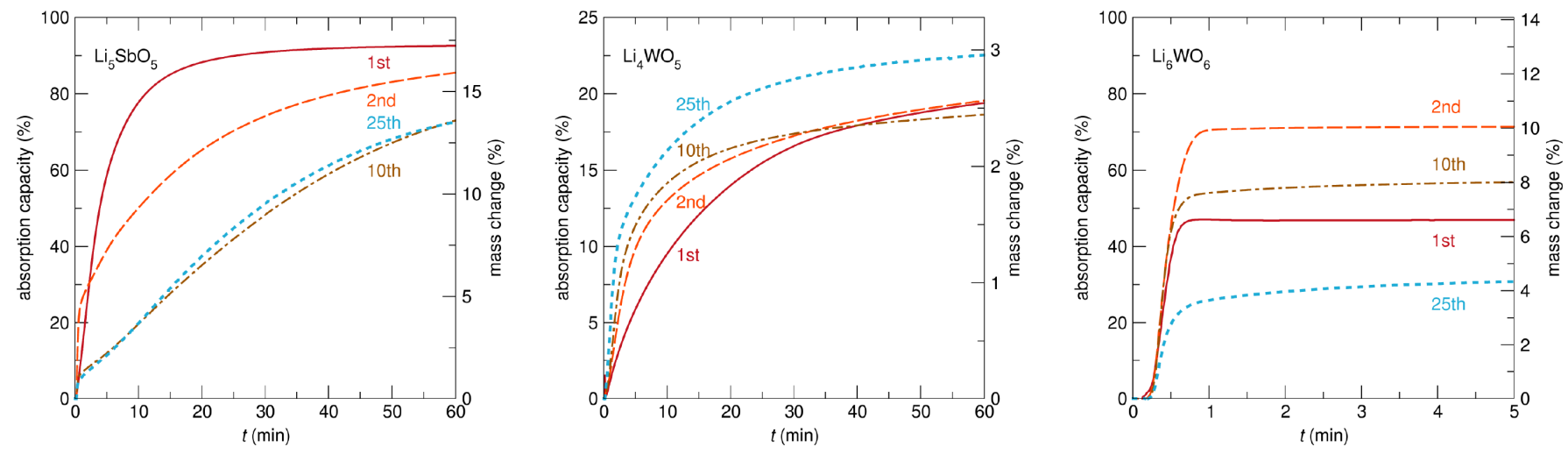

FIG. 3. Selected carbonation profiles for $\mathrm{Li}_{5} \mathrm{SbO}_{5}, \mathrm{Li}_{4} \mathrm{WO}_{5}$ and $\mathrm{Li}_{6} \mathrm{WO}_{6}$ from extended carbonation cycling experiments. Both $\mathrm{Li}_{5} \mathrm{SbO}_{5}$ and $\mathrm{Li}_{6} \mathrm{WO}_{6}$ show a decrease in capacity after 25 cycles, with $\mathrm{Li}_{5} \mathrm{SbO}_{5}$ in particular showing a much flatter absorption profile. $\mathrm{Li}_{4} \mathrm{WO}_{5}$ retains both its profile and capacity for the duration of the cycling, albeit with the lowest capacity of the three materials.

theoretical sorption capacity is reached, after 25 cycles this is doubled; $\mathrm{Li}_{4} \mathrm{WO}_{5}$ absorbs $13 \%$ of the theoretical capacity after the same exposure time (5 min).

D. Structural and morphological evolution of $\mathrm{Li}_{5} \mathrm{SbO}_{5}$ upon cycling

$\mathrm{Li}_{5} \mathrm{SbO}_{5}$ was found to be the material with the most promising thermodynamics of carbonation and capacity retention, so it was subjected to further in-depth structural and morphological characterisation to examine changes as a function of cycle number. Samples were extracted at different points in the cycling experiment and analysed using XRD and scanning electron microscopy (SEM). The resulting diffractograms were analysed and the phase fractions in the regenerated material were determined through Rietveld refinement (Figure 5). Diffractograms and fits are available in the Supporting Information.

The phase composition of $\mathrm{Li}_{5} \mathrm{SbO}_{5}$ after cycling remains relatively stable up to at least three cycles, and is a mixture of $\sim 83-86 \mathrm{wt} . \% \mathrm{Li}_{5} \mathrm{SbO}_{5}, \sim 12-15 \mathrm{wt} . \% \mathrm{Li}_{3} \mathrm{SbO}_{4}$ and $\sim 2-3 \mathrm{wt} . \% \mathrm{Li}_{7} \mathrm{SbO}_{6}$ (Figure 5). The formation of a secondary phase with a higher lithium content upon regeneration is surprising considering this behaviour has never been seen for other similar materials, but may play a role in the stable cycling capacity observed for the material. In addition to the formation of $\mathrm{Li}_{7} \mathrm{SbO}_{6}$, there is also significant formation of $\mathrm{Li}_{3} \mathrm{SbO}_{4}$, which does not react upon regeneration under inert atmosphere at higher temperature. TGA experiments on single-phase $\mathrm{Li}_{3} \mathrm{SbO}_{4}$ prepared separately indicate this phase is inert with respect to carbonation (see Supporting Information), so this represents a permanent loss in capacity, as seen in the cycling TGA experiments discussed earlier.

The phase composition of $\mathrm{Li}_{5} \mathrm{SbO}_{5}$ eventually does evolve with repeated cycling, and after 26 carbonation cycles the fraction of $\mathrm{Li}_{5} \mathrm{SbO}_{5}$ formed upon regeneration decreases to $55 \mathrm{wt} . \%$. However, $\mathrm{Li}_{7} \mathrm{SbO}_{6}$ is formed in a much greater proportion (21 wt.\%) than in the early cycles, and is present in roughly the same proportion as $\mathrm{Li}_{3} \mathrm{SbO}_{4}$ (24wt.\%). The higher lithium content in $\mathrm{Li}_{7} \mathrm{SbO}_{6}$ decreases the stability of the phase with respect to $\mathrm{CO}_{2}$, so unlike $\mathrm{Li}_{3} \mathrm{SbO}_{4}$, we expect $\mathrm{Li}_{7} \mathrm{SbO}_{6}$ to be much more reactive to $\mathrm{CO}_{2}$. Consequently, although the fraction of the original phase being regenerated decreases with increased cycling, the capacity of $" \mathrm{Li}_{5} \mathrm{SbO}_{5}$ " as a material remains relatively stable due to the formation of $\mathrm{Li}_{7} \mathrm{SbO}_{6}$. 


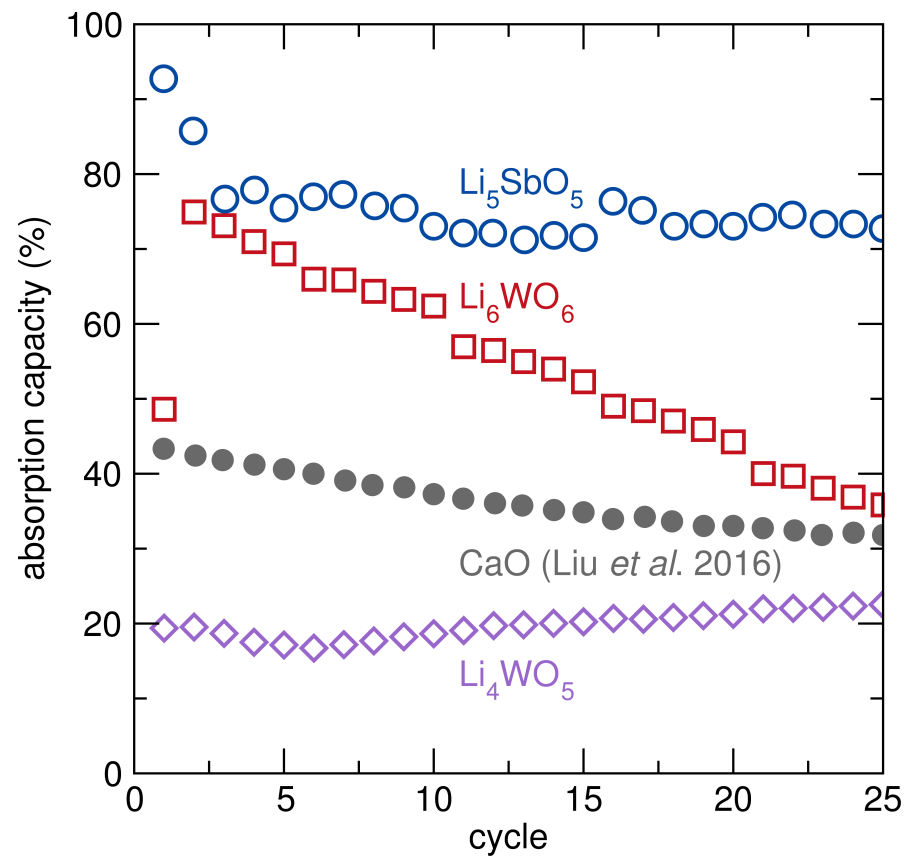

FIG. 4. The percentage absorption capacity measured for each of $\mathrm{Li}_{5} \mathrm{SbO}_{5}, \mathrm{Li}_{6} \mathrm{WO}_{6}$ and $\mathrm{Li}_{4} \mathrm{WO}_{5}$ over the 25 carbonation and regeneration looping cycles. $\mathrm{Li}_{5} \mathrm{SbO}_{5}$ displays sustained capacity retention after the first 3 cycles; $\mathrm{Li}_{4} \mathrm{WO}_{5}$ actually shows an increase in capacity overall. The $\mathrm{Li}_{6} \mathrm{WO}_{6}$ displays less favourable looping behaviour, with a steady loss in capacity from cycle 2 onwards. The results for $\mathrm{CaO}$ were calculated using data courtesy of Liu et al. ${ }^{[2]}$ and have been included for comparison.

The SEM micrographs, shown in Figure 6, also give an insight into the microstructural evolution of $\mathrm{Li}_{5} \mathrm{SbO}_{5}$ upon cycling. After the first carbonation step, the formation of $\mathrm{Li}_{2} \mathrm{CO}_{3}$ can be seen in the apparent coarsening of the $\mathrm{Li}_{5} \mathrm{SbO}_{5}$ particles, in line with the observations in previous SEM experiments of carbonated materials such as $\mathrm{Na}_{3} \mathrm{SbO}_{4} \cdot \frac{15]}{\text { Th }}$ This surface area is recreated upon regeneration, and the image at higher magnification shows that the finer structural features on the surface of the particles are also regenerated. Crucially, the images taken at the same point in the carbonation cycle after 26 cycles show a similar surface area and size of the secondary particles. The primary particles are larger and less fused together following multiple cycles, which supports the stable cycling capacity seen in the material.

\section{E. Discussion}

The benefit of a large scale screening is that it allows broader insight into trends and underlying causes of observed physical properties. This study is the latest in a growing body of work experimentally characterising the $\mathrm{CO}_{2}$ absorption properties of promising ternary oxides, and the results can be compared to previous work to bet-

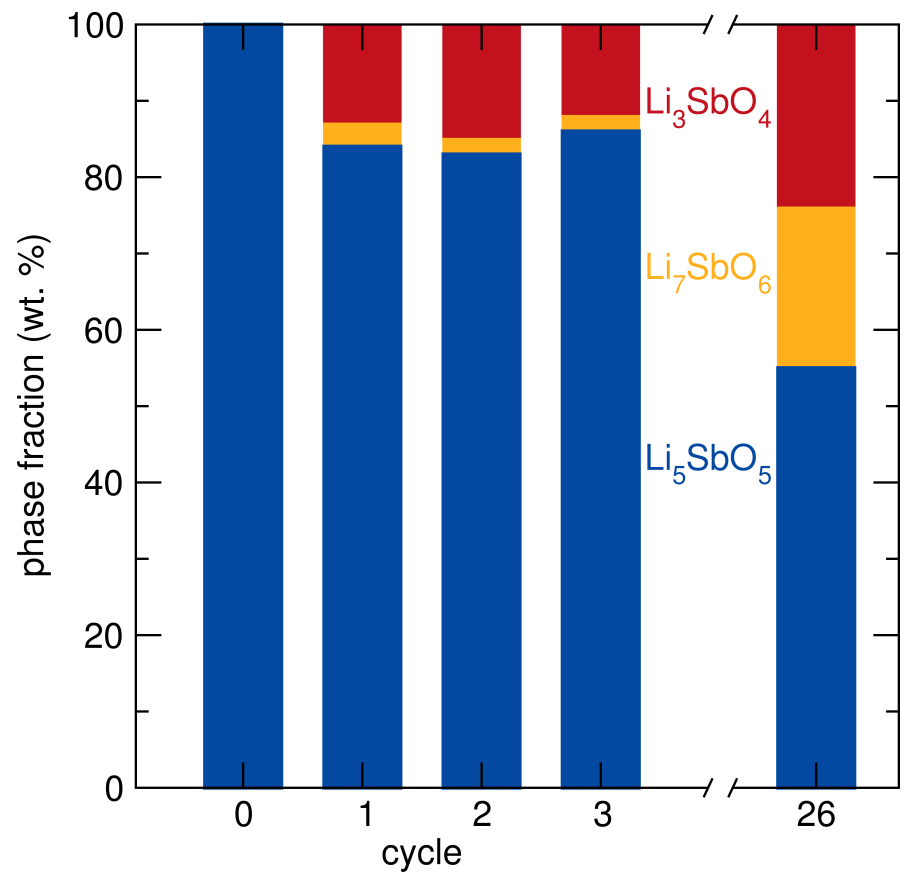

FIG. 5. Phase fraction evolution of regenerated $\mathrm{Li}_{5} \mathrm{SbO}_{5}$ as a function of cycle number, as determined by Rietveld refinement. Upon repeated carbonation cycles, less $\mathrm{Li}_{5} \mathrm{SbO}_{5}$ is formed upon regeneration, but overall $\mathrm{CO}_{2}$ sorption capacity is unchanged due to the formation of unreactive $\mathrm{Li}_{3} \mathrm{SbO}_{4}$ and reactive $\mathrm{Li}_{7} \mathrm{SbO}_{6}$.

ter understand the key factors in carbonation reactions.

We examine the role of metal ion and crystal structure by comparing alkali transition metal oxides adopting the antifluorite-type structure. These phases have similar crystal structures and compositions, and differ primarily in the identity of the transition metal in the material. The materials include $\mathrm{Li}_{6} \mathrm{MnO}_{4}, \mathrm{Li}_{6} \mathrm{ZnO}_{4}$, and $\mathrm{Li}_{6} \mathrm{CoO}_{4}$ (studied in this work), as well as $\mathrm{Li}_{5} \mathrm{FeO}_{4} \frac{15}{15}$ and $\mathrm{Li}_{5} \mathrm{AlO}_{4} \cdot \frac{12}{12}$ These materials all show remarkably similar carbonation profiles, with the onset of a small initial mass gain at low temperature around $\sim 600 \mathrm{~K}$, followed by a sharp onset and substantial mass gain at higher temperatures initiated between $850 \mathrm{~K}$ and $900 \mathrm{~K}$. This is sensible given the carbonation reactions of these materials calculated in this work have very similar $\Delta E^{\mathrm{DFT}}$, with values ranging from $-2.16 \mathrm{eV}$ to $-2.32 \mathrm{eV}$. This family of materials display similar carbonation capacities, with experimental values ranging from $82 \%$ of theoretical capacity for $\mathrm{Li}_{6} \mathrm{CoO}_{4}$ studied in this work, to $96 \%$ for $\mathrm{Li}_{5} \mathrm{AlO}_{4} \cdot 12$

Looking across these lithium-rich antifluorite-type materials, the choice of metal in these materials is not critical, and given the reasonable carbonation properties across the family, targeting specific structure types may be an efficient and fruitful direction for future rational design. Here, the thermodynamic driving force and high capacities are enabled by the high lithium content. Meanwhile, the good kinetics and remarkably fast 

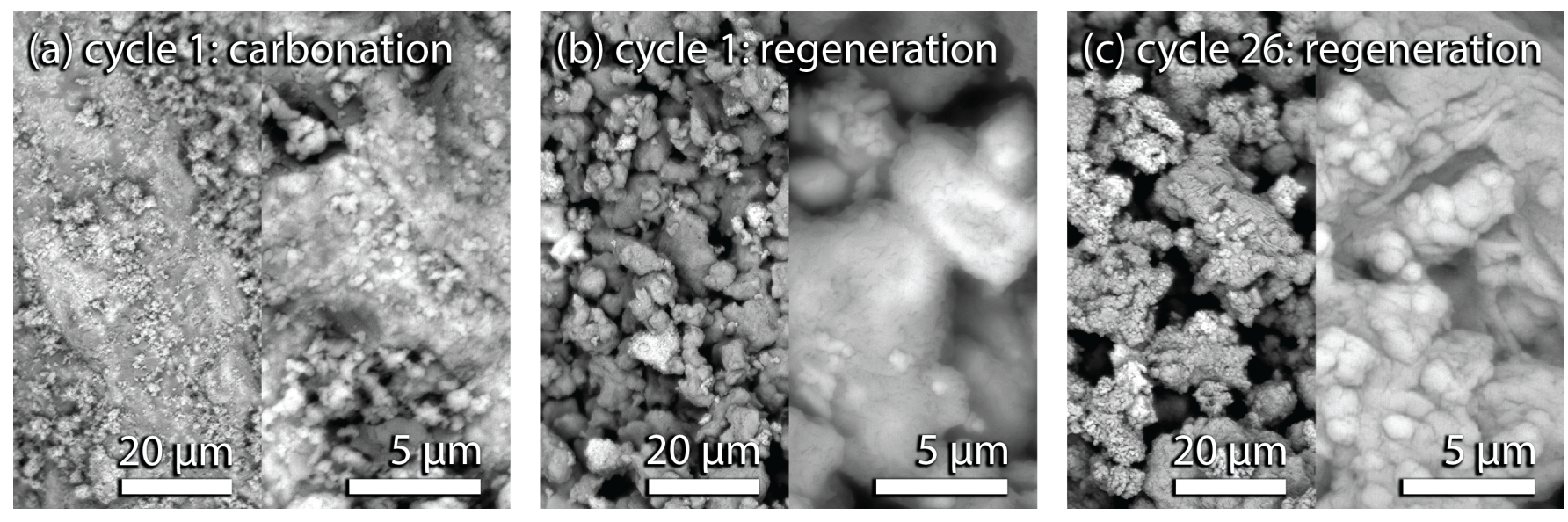

FIG. 6. Scanning electon micrographs of $\mathrm{Li}_{5} \mathrm{SbO}_{5}$ after (a) the 1st carbonation, (b) the 1st regeneration, and (c) the 26th regeneration. Both regenerated specimens display similar morphology and no sign of coarsening, suggesting the microstructure is conserved upon repeated cycling.

$\mathrm{CO}_{2}$ absorption seen at higher temperatures are likely enabled by the many partially-occupied Li sites in the crystal structure, which lead to high rates of Li transport through the material once defect-mediated transport mechanisms are activated.

Despite the promising $\mathrm{CO}_{2}$ sorption capacities and rates, this study found $\mathrm{Li}_{6} \mathrm{MnO}_{4}$ and $\mathrm{Li}_{6} \mathrm{ZnO}_{4}$ could not be regenerated and hence cycled, in a similar fashion to the related materials $\mathrm{Li}_{5} \mathrm{FeO}_{4}$ and $\mathrm{Li}_{6} \mathrm{CoO}_{4} \cdot \frac{15}{15}$ Other methods will thus be required to make these materials appropriate for looping applications. One strategy that has been shown to be successful is the inclusion of water vapour in the reactant gas stream which led to a significant decrease in the temperature required for regeneration of $\mathrm{Li}_{5} \mathrm{AlO}_{4} \cdot{ }^{21} \mathrm{~A}$ similar strategy that shifts the carbonation equilibrium temperature may very well work with the entire class of antifluorite materials, and future work is planned to investigate this and the overall role water plays in $\mathrm{CO}_{2}$ absorption and regeneration cycles.

The surprising cycling behaviour of $\mathrm{Li}_{5} \mathrm{SbO}_{5}$ and the formation of increasing amounts of the over-lithiated phase $\mathrm{Li}_{7} \mathrm{SbO}_{6}$ opens a new route towards finding new ternary systems that maintain their cycling capacity. Instead of relying upon complete regeneration of the original material, if there are other phases with similar composition and reactivity that can be accessed during the reaction, their creation can counteract the loss of capacity caused by coarsening and the permanent formation of inert phases. Furthermore the SEM images indicate that $\mathrm{Li}_{7} \mathrm{SbO}_{6}$ may indeed form with similar morphology as the original $\mathrm{Li}_{5} \mathrm{SbO}_{5}$ phase, leading to little decline in reactivity with cycling. The fact these phases might be metastable $\left(\mathrm{Li}_{7} \mathrm{SbO}_{6}\right.$ lies $0.008 \mathrm{eV}$ above the hull in the Li-Sb-O phase diagram calculated by the Materials Project) means future screenings should include metastable materials close to the hull, otherwise potential reaction pathways that can be accessed under car- bonation cycling conditions might be missed.

As seen in previous studies on $\mathrm{Ba}_{4} \mathrm{Sb}_{2} \mathrm{O}_{9}, 14$ conservation of capacity and morphology are strongly linked, a phenomenon that is the subject of ongoing analysis and effort to also include in future screening methodologies. The SEM of $\mathrm{Li}_{5} \mathrm{SbO}_{5}$ further supports these earlier studies, even if the underlying causes for microstructure retention are not known. There is nevertheless a degradation in the absorption rate of $\mathrm{Li}_{5} \mathrm{SbO}_{5}$ as the material is cycled, which is an opportunity for future studies aimed at achieving capacity retention rates comparable to those obtained following steam injection in the $\mathrm{CaO}$ system. 22-24

The absolute capacity of $\mathrm{Li}_{4} \mathrm{WO}_{5}$ is the lowest amongst the materials in this study, and would certainly require larger amounts of material to be used in CCS applications, but this is not necessarily an insurmountable barrier to its implementation. $\mathrm{Li}_{4} \mathrm{WO}_{5}$ is predominantly composed of Li-O, with a low loading of W. Consequently, the total mass needed to achieve a certain gravimetric $\mathrm{CO}_{2}$ absorption value would be comparable to heavier materials with better capacities, such as $\mathrm{Li}_{5} \mathrm{SbO}_{5}$ or $\mathrm{Ba}_{4} \mathrm{Sb}_{2} \mathrm{O}_{9}$. Furthermore, certain CCS applications do not require particularly high capacities. In particular, CCS applications on a smaller scale than power generation, such as improving hydrogen yields in chemical looping processes 25 or chemical looping partial oxidation of methane, $\stackrel{26}{2}$ rely on efficient and complete regeneration over many cycles, properties displayed by $\mathrm{Li}_{4} \mathrm{WO}_{5}$. This finding highlights the advantage of large scale screening methods in that materials can be found for different target applications in the same experiment, and further selected on various criteria.

A final interesting observation arising from the screening comes when considering the materials that were predicted to carbonate but failed to do so in experiments. This group of materials had low predicted tem- 
peratures of carbonation, where under atmosphere of $p_{\mathrm{CO}_{2}}<1 \times 10^{5} \mathrm{~Pa}, T_{\text {carbonation }} \lesssim 600 \mathrm{~K}: \mathrm{CaWO}_{4}(323 \mathrm{~K})$, $\mathrm{Li}_{2} \mathrm{WO}_{4}(503 \mathrm{~K}), \mathrm{Ca}_{4} \mathrm{Nb}_{2} \mathrm{O}_{9}(606 \mathrm{~K}), \mathrm{Li}_{3} \mathrm{NbO}_{4}(503 \mathrm{~K})$, $\mathrm{Li}_{3} \mathrm{TaO}_{4}(511 \mathrm{~K})$ and $\mathrm{Li}_{3} \mathrm{SbO}_{4}(532 \mathrm{~K})$. Considering the earlier studies investigating the connection between carbonation and ionic mobility, ${ }^{27-29}$ these results suggest a material may not carbonate at low temperatures due to insufficient ionic mobility, even if a material is predicted to carbonate based on thermodynamics. As the temperature is increased into a region where ionic mobility might be sufficient, the equilibrium may favour regeneration (i.e., decarbonation) rather than carbonation, leading to further inactivity.

The need to balance two competing factors for the development of successful CCS materials is important for future studies. The carbonation temperature must be low enough to avoid particle coarsening, which leads to loss of capacity as in the pure $\mathrm{CaO}-\mathrm{CaCO}_{3}$ system. However, the carbonation temperature cannot be so low as to hinder ionic diffusion in the material and cause slow carbonation kinetics. This also explains the anomalous materials that carbonate at low temperature: owing to the smaller ionic radius and charge of $\mathrm{Li}^{+}$when compared to $\mathrm{Ca}^{2+}$, one would expect faster ionic diffusion in $\mathrm{Li}_{4} \mathrm{WO}_{5}$ at lower temperatures than $\mathrm{Ca}$ analogues (e.g., $\mathrm{CaWO}_{4}$ and $\mathrm{Ca}_{3} \mathrm{WO}_{6}$ ), and hence we observe some carbonation of $\mathrm{Li}_{4} \mathrm{WO}_{5}$ even at the low temperatures where the Cabased materials do not react. The difficulty in achieving sufficient $\mathrm{Ca}$ ionic diffusion means that even with a reasonably high carbonation temperature the reaction does not occur. Thus, thermodynamic screening needs to be carried out in concert with screening for ionic diffusivity, a methodology that is the focus of ongoing work. Focusing only on decreasing the energy penalty of the chosen material needs to be balanced with other parameters that influence actual performance.

\section{CONCLUSIONS}

In this study we used the theoretical screening of structural databases as a starting point for exploring novel materials for use in high-temperature carbon capture and storage (CCS) applications. Diverse candidate materials were selected, and either displayed desirable theoretical properties or allowed direct compositional and/or structural comparisons to previously studied materials. These candidates were subjected to a suite of structural and thermogravimetric experiments to determine their performance as $\mathrm{CO}_{2}$ looping materials.

In the first instance, this initial testing reveals that the theoretical screening accurately predicts the carbonation temperature of the candidate materials studied here, but fails to identify materials whose carbonation is hindered by poor kinetics. $\mathrm{Li}_{5} \mathrm{SbO}_{5}, \mathrm{Li}_{6} \mathrm{WO}_{6}$ and $\mathrm{Li}_{4} \mathrm{WO}_{5}$ all exhibit reversible $\mathrm{CO}_{2}$ sorption, with $\mathrm{Li}_{5} \mathrm{SbO}_{5}$ showing a particularly high and stable capacity retention over 25 carbonation cycles. $\mathrm{Li}_{5} \mathrm{SbO}_{5}$ has a stable microstruc- ture that is preserved through repeated cycling; scanning electron micrographs of " $\mathrm{Li}_{5} \mathrm{SbO}_{5}$ " after regeneration do not reveal any significant evolution of morphology after 25 cycles. Further structural analysis at different stages of cycling reveals the formation of a secondary metastable phase upon reaction, $\mathrm{Li}_{7} \mathrm{SbO}_{6}$, which may prevent coarsening and deactivation of the sorbent. This phase space, where there are many easily accessible stoichiometries upon reaction that are close in energy, could prove fertile ground for the design of new robust CCS materials.

Further analysis of the candidate materials studied here in concert with the body of previous research carried out by authors in this work hint at other important design principles for future research, the most crucial being the need to use a moderate temperature to satisfy both energetic and diffusion considerations in $\mathrm{CO}_{2}$ absorption materials. The design of new materials, as well as the chemical and structural modification of exisiting materials, need to consider these two factors to find a suitable reaction temperature that has favourable thermodyanamic driving force as well as sufficiently fast ionic transport. The performance of materials in CCS applications is the result of a delicate balance between thermodynamics, ion diffusion, and morphology, and requires a similarly balanced mix of theoretical, synthetic and analytical approaches to fully understand how to harness these competing forces.

\section{ACKNOWLEDGMENTS}

The authors thank Zlatko Sarakevic for carrying out the BET experiments, and Wen Liu, Stuart Scott and John Dennis for fruitful discussions regarding the work and assistance with the TGA experiments. The authors also gratefully acknowledge Anubhav Jain (Computational Research Division, Lawrence Berkeley National Laboratory), Shyue Ping Ong (Department of NanoEngineering, University of California San Diego) and Kristin Persson (Department of Materials Science and Engineering, University of California Berkeley) for their advice and assistance in accessing the Materials Project, which itself is supported through the U.S. Department of Energy, Office of Basic Energy Sciences, Materials Project Center Grant No. EDCBEE. MWG is grateful for support from the European Union's Horizon 2020 research and innovation programme under the Marie Skłodowska-Curie grant agreement No. 659764. MTD and CPG acknowledge funding from EPSRC Grant No. EP/K030132/1. MTD is grateful for support from Clare College, Cambridge through the award of a Junior Research Fellowship.

\section{DATA}

All supporting data for this work can be found on https://www.repository.cam.ac.uk. 


\section{SUPPORTING INFORMATION}

XRD diffractograms and Rietveld refinements for the candidate materials, surface area measurements, XRD diffractograms of $\mathrm{Li}_{5} \mathrm{SbO}_{5}$ at different stages of carbonation cycle, and TGA traces for candidate materials. This material is free of charge via the Internet at http://pubs.acs.org.

\section{REFERENCES}

${ }^{1}$ A. D. Ebner and J. A. Ritter, "State-of-the-art adsorption and membrane separation processes for carbon dioxide production from carbon dioxide emitting industries," Separ. Sci. Technol. 44, 1273-1421 (2009)

${ }^{2}$ D. P. Hanak, E. J. Anthony, and V. Manovic, "A review of developments in pilot-plant testing and modelling of calcium looping process for $\mathrm{CO}_{2}$ capture from power generation systems," Energy Environ. Sci. 8, 2199-2249 (2015)

${ }^{3}$ A. M. Kierzkowska, R. Pacciani, and C. R. Müller, "CaO-based $\mathrm{CO}_{2}$ sorbents: From fundamentals to the development of new, highly effective materials," ChemSusChem 6, 1130-1148 (2013)

${ }^{4}$ E. Bouquet, G. Leyssens, C. Schönnenbeck, and P. Gilot, "The decrease of carbonation efficiency of $\mathrm{CaO}$ along calcinationcarbonation cycles: Experiments and modelling," Chem. Eng. Sci. 64, 2136-2146 (2009)

${ }^{5} \mathrm{~K}$. Nakagawa and T. Ohashi, "A novel method of $\mathrm{CO}_{2}$ capture from high temperature gases," J. Electrochem. Soc. 145, 1344-1346 (1998)

${ }^{6} \mathrm{~K}$. Nakagawa and T. Ohashi, "A reversible change between lithium zirconate and zirconia in molten carbonate," Electrochem. 67, 618621 (1999)

${ }^{7}$ A. López-Ortiz, N. G. P. Rivera, A. R. Rojas, and D. L. Gutierrez, "Novel carbon dioxide solid acceptors using sodium containing oxides," Sep. Sci. Technol. 39, 3559-3572 (2004)

${ }^{8}$ T. Zhao, E. Ochoa-Fernández, M. Rønning, and D. Chen, "Preparation and high-temperature $\mathrm{CO}_{2}$ capture properties of nanocrystalline $\mathrm{Na}_{2} \mathrm{ZrO}_{3}$," Chem. Mater. 19, 3294-3301 (2007)

${ }^{9}$ T. Yamaguchi, T. Niitsuma, B. N. Nair, and K. Nakagawa, "Lithium silicate based membranes for high temperature $\mathrm{CO}_{2}$ separation," J. Membr. Sci. 294, 16-21 (2007)

${ }^{10}$ M. J. Venegas, E. Fregoso-Israel, R. Escamilla, and H. Pfeiffer, "Kinetic and reaction mechanism of $\mathrm{CO}_{2}$ sorption on $\mathrm{Li}_{4} \mathrm{SiO}_{4}$ : Study of the particle size effect," Ind. Eng. Chem. Res 46, 2407-2412 (2007)

${ }^{11}$ T. Ávalos-Rendón, J. Casa-Madrid, and H. Pfeiffer, "Thermochemical capture of carbon dioxide on lithium aluminates $\left(\mathrm{LiAlO}_{2}\right.$ and $\mathrm{Li}_{5} \mathrm{AlO}_{4}$ ): A new option for the $\mathrm{CO}_{2}$ absorption," J. Phys. Chem A 113, 6919-6923 (2009).

${ }^{12}$ T. Ávalos-Rendón, V. H. Lara, and H. Pfeiffer, " $\mathrm{CO}_{2}$ chemisorption and cyclability analyses of lithium aluminate polymorphs ( $\alpha$ - and $\beta$ $\mathrm{Li}_{5} \mathrm{AlO}_{4}$ )," Ind. Eng. Chem. Res 51, 2622-2630 (2012)

${ }^{13}$ H. A. Lara-García, P. Sanchez-Camacho, Y. Duan, J. Ortiz-Landeros, and $\mathrm{H}$. Pfeiffer, "Analysis of the $\mathrm{CO}_{2}$ chemisorption in $\mathrm{Li}_{5} \mathrm{FeO}_{4}$, a new high temperature $\mathrm{CO}_{2}$ captor material. effect of the $\mathrm{CO}_{2}$ and $\mathrm{O}_{2}$ partial pressures," J. Phys. Chem. C 121, 2455-3462 (2017).

${ }^{14}$ M. T. Dunstan, W. Liu, A. F. Pavan, J. A. Kimpton, C. D. Ling, S. A. Scott, J. S. Dennis, and C. P. Grey, "Reversible $\mathrm{CO}_{2}$ absorption by the $6 \mathrm{H}$ perovskite $\mathrm{Ba}_{4} \mathrm{Sb}_{2} \mathrm{O}_{9}$," Chem. Mater. 25, 4881-4891 (2013).

${ }^{15}$ M. T. Dunstan, A. Jain, W. Liu, S. P. Ong, T. Liu, J. Lee, K. A. Persson, S. A. Scott, J. S. Dennis, and C. P. Grey, "Large scale computational screening and experimental discovery of novel materials for high temperature $\mathrm{CO}_{2}$ capture," Energy Environ. Sci. 9, 1346-1360 (2016)

${ }^{16}$ D. Cruz, S. Bulbulian, E. Lima, and H. Pfeiffer, "Kinetic analysis of the thermal stability of lithium silicates $\left(\mathrm{Li}_{4} \mathrm{SiO}_{4}\right.$ and $\left.\mathrm{Li}_{2} \mathrm{SiO}_{3}\right)$," J. Solid State Chem. 179, 909-916 (2006).
${ }^{17}$ A. A. Coelho, "TOPAS and TOPAS-Academic: An optimization program integrating computer algebra and crystallographic objects written in C++," J. Appl. Crystallogr. 51, 210-218 (2018).

${ }^{18} \mathrm{~S}$. Brunauer, P. H. Emmett, and E. Teller, "Adsorption of gases in multimolecular layers," J. Am. Chem. Soc. 60, 309-319 (1938).

${ }^{19}$ J. Hauck, "Zur kristallstruktur des $\mathrm{Li}_{6} \mathrm{WO}_{6}$," Z. Naturforsch. B 24, 251 (1969).

${ }^{20}$ W. Liu, B. González, M. T. Dunstan, D. S. Sultan, A. Pavan, C. D. Ling, C. P. Grey, and J. Dennis, "Structural evolution in synthetic, Ca-based sorbents for carbon capture," Chem. Eng. Sci. 139, 15-26 (2016)

${ }^{21}$ T. L. Avvalos-Rendón and H. Pfeiffer, "High $\mathrm{CO}_{2}$ chemisorption in $\alpha$ $\mathrm{Li}_{5} \mathrm{AlO}_{4}$ at low temperatures $\left(30-80^{\circ} \mathrm{C}\right)$ : Effect of the water vapor addition," Energy Fuels 26, 3110-3114 (2012)

${ }^{22}$ V. Nikulshina, M. E. Gálvez, and A. Steinfeld, "Kinetic analysis of the carbonation reactions for the capture of $\mathrm{CO}_{2}$ from air via the $\mathrm{Ca}(\mathrm{OH})_{2}-\mathrm{CaCO}_{3}-\mathrm{CaO}$ solar thermochemical cycle," Chem. Eng. J. 129, 75-83 (2007)

${ }^{23} \mathrm{~V}$. Manovic and E. J. Anthony, "Carbonation of CaO-based sorbents enhanced by steam addition," Ind. Eng. Chem. Res 49, 9105-9110 (2010)

${ }^{24}$ I. Lindén, P. Backman, A. Brink, and M. Hupa, "Influence of water vapor on carbonation of $\mathrm{CaO}$ in the temperature range $400-550^{\circ} \mathrm{C}$," Ind. Eng. Chem. Res 50, 14115-14120 (2011)

${ }^{25}$ M. S. C. Chan, W. Liu, M. Ismail, Y. Yang, S. A. Scott, and J. S. Dennis, "Improving hydrogen yields, and hydrogen:steam ratio in the chemical looping production of hydrogen using $\mathrm{Ca}_{2} \mathrm{Fe}_{2} \mathrm{O}_{5}$," Chem. Eng. J. 296, 406-411 (2016)

${ }^{20}$ S. Bhavsar and G. Veser, "Chemical looping beyond combustion: Production of synthesis gas via chemical looping partial oxidation of methane," RSC Adv. 4, 47254-47267 (2014).

${ }^{27}$ J.-i. Ida and Y. S. Lin, "Mechanism of high-temperature $\mathrm{CO}_{2}$ sorption on lithium zirconate," Environ. Sci. Technol. 37, 1999-2004 (2003)

${ }^{28}$ M. T. Dunstan, J. M. Griffin, F. Blanc, M. Leskes, and C. P. Grey, "Ion dynamics in $\mathrm{Li}_{2} \mathrm{CO}_{3}$ studied by solid-state NMR and first-principles calculations," J. Phys. Chem. C 119, 24255-24264 (2015).

${ }^{29}$ M. T. Dunstan, H. Laeverenz Schlogelhofer, J. M. Griffin, M. S. Dyer, M. W. Gaultois, C. Y. Lau, S. A. Scott, and C. P. Grey, "Ion dynamics and $\mathrm{CO}_{2}$ absorption properties of Nb-, Ta-, and Y-doped $\mathrm{Li}_{2} \mathrm{ZrO}_{3}$ studied by solid-state NMR, thermogravimetry, and first-principles calculations,"J. Phys. Chem. C 121, 21877-21886 (2017). 


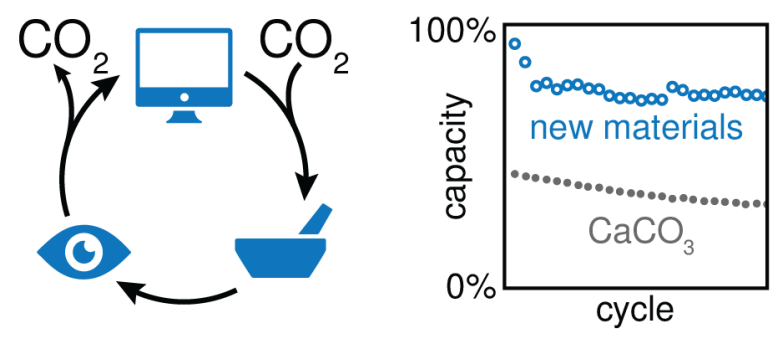

TOC graphic 